Asian-Australasian Journal of

Food Safety and Security

ISSN 2523-1073 (Print) 2523-2983 (Online)

www.ebupress.com/journal/aajfss

\title{
Article \\ Different perspectives associated with the development of relevant strategies for maintenance of withdrawal period of veterinary drugs: Bangladesh perspectives
}

\author{
Md. Zobidul Kabir ${ }^{1}$, Alam Khan², Md. Jahanur Rahman ${ }^{3}$ and Moizur Rahman ${ }^{4 *}$ \\ ${ }^{1}$ Institute of Environmental Science, University of Rajshahi and Upazila Livestock Officer, Rajarhat, Kurigram, \\ Bangladesh \\ ${ }^{2}$ Department of Pharmacy, University of Rajshahi, Rajshahi-6205, Bangladesh \\ ${ }^{3}$ Department of Statistics, University of Rajshahi, Rajshahi-6205, Bangladesh \\ ${ }^{4}$ Department of Veterinary \& Animal Sciences, University of Rajshahi, Rajshahi-6205, Bangladesh
}

*Corresponding author: Moizur Rahman, Department of Veterinary \& Animal Sciences, University of Rajshahi, Rajshahi-6205, Bangladesh. E-mail: moizur@ru.ac.bd

Received: 03 November 2018/Accepted: 24 November 2018/ Published: 29 November 2018

\begin{abstract}
Veterinary drugs have proven to be one of the most valuable tools in preserving animal health. With an increase in the use and availability of veterinary drugs, residues of veterinary drugs in animal origin food has become a public health concern and has received much attention from government agencies, consumer level, media and other concerned public interest groups. The objectives of the study were to identify the perspectives associated with the poor management for maintenance of withdrawal period of veterinary drugs in Bangladesh so that the development of relevant strategies for maintenance of withdrawal period of veterinary drugs could be achieved in context of environmental realities in Bangladesh. The survey was interpretive in nature using quantitative methods. A non-experimental and descriptive research design was used to conduct this study. The survey study was carried out at seven divisions (i.e. Rangpur, Rajshahi, Khulna, Dhaka, Sylhet, Barishal and Chattogram) in Bangladesh during July 2012 to June 2018 by using close ended questionnaires among randomly selected respondents. Survey instruments were also designed to capture the perspectives of two different groups of government veterinarians: Group 1- Veterinary Surgeons of DLS, Bangladesh and Group 2 -Upazila Livestock Officers of DLS, Bangladesh. The findings indicated the knowledge, beliefs and perceptions of respondents. The research findings divulge that different perspectives/dimensions associated with economic loss, compensation support, awareness, ethical motivation, monitoring system, proper legislation and guideline, cooperative and group livestock production as well as marketing system had 'moderate to substantial role' with the management for maintenance of withdrawal period of veterinary drugs in Bangladesh. Besides these, findings also indicated that other perspectives/dimensions associated with allocation of subsidies and Bank loan with low interest, opportunity of livestock/ poultry insurance services, capacity enhancement for monitoring system, availability of technology to producers level, extension work with motivation, magistracy empowerment for veterinarians, legal influence, capacity enhancement of DLS staff, building of public awareness on drug residue problem and availability of effective equipment as well as modern analytical techniques for diagnostic analysis of chemical/drug residues also had 'moderate to substantial role' with the development of relevant strategies for maintenance of withdrawal period of veterinary drugs. Findings indicated that the two groups of veterinarians possessed near to similar/same perceptions across different dimensions/perspectives associated with the development of relevant strategies for maintenance of withdrawal period of veterinary drugs in Bangladesh and that no significant differences in perspectives existed ( $p>.05)$. Findings of this study could be implemented for formulation of effective policy as well as guideline with the development of relevant strategies for maintenance of withdrawal period of veterinary drugs in context of environmental realities in Bangladesh.
\end{abstract}

Keywords: perspectives; relevant strategies; withdrawal period; veterinary drugs 


\section{Introduction}

Veterinary drugs are rationally important to meet the challenges for providing adequate amounts of food for the growing world population (Crawford, 1985) as veterinary drugs are interlinked to improve the rate of weight gain, improvement of feed efficiency, or effective to prevent as well as treatment of diseases in food producing animals (Crawford, 1985). However, the benefit of improved production from the use of veterinary drugs in food producing animals is not gained without the risk associated with drug residues that persist in the tissues of treated animals at the time of slaughter (Sarker et al., 2018). Antibacterial drugs and hormonal growth promoters are important preparations of Veterinary drugs that potentially contaminate foods of animal origin (Takele et al., 2015).

Adulteration of the food supply chain with antimicrobial agents, pesticides, environmental contaminants, and other chemicals has been treated as relevant source of concern to the general public and concerning stakeholder groups (Riviere and Sundolf, 2009; Islam et al., 2016). Antimicrobial drugs are increasingly used in therapeutic treatment of livestock and poultry and become an important factor of the drug residues in the livestock as well as poultry products and their byproducts (Amjad and Habib, 2005). Drugs given to birds and animals both orally or parentally might be in concerning tissues, particularly when the birds or animals are slaughtered without observance of withdrawal period or when milk or eggs are harvested as well as provided within the withdrawal period of the drug (Althaus et al., 2003). It was also reported that the most relevant reason for unacceptable residues in concerning tissuesof livestock might be due to failure to keep to the withdrawal period of veterinary drugs (Beyene and Tesega, 2014).

Considering the importance of withdrawal period of veterinary drugs in wholesome as well as safe animal origin food production in community, this article mentioned some important perspectives associated with the poor/weak management in maintenance of withdrawal period of veterinary drugs in Bangladesh. Finally, this article identified some strategies for maintaining withdrawal period of veterinary Drugs in context of environmental realities in Bangladesh.

\section{Materials and Methods}

\subsection{Research design}

The survey was interpretive in nature using quantitative methods. A non - experimental and descriptive research design was considered to develop this study (Creswell and Clark, 2011).

\subsection{Study area, population, sample and sampling}

In this study, the samples were collected from following two different stakeholder groups:

Group 1: Government Veterinary Surgeons of existing seven divisions of Bangladesh (e.g. Rangpur, Rajshahi, Khulna, Barishal, Sylhet, Chittagong and Dhaka).

Group 2: Government Upazila Livestock officers (Only Veterinarians/DVM degree holder, but not any graduate of Animal Husbandry/B.Sc.in A.H. degree holder) of existing seven divisions of Bangladesh (e.g. Rangpur, Rajshahi, Khulna, Barishal, Sylhet, Chittagong and Dhaka).

Considering the existing organogram of DLS (Collected from Website of DLS in 2012 \&and Bangladesh Veterinarians' Directory, 2012) and the total number of organized and old Govt. upazila/sub district Livestock Office of DLS, 460 number of Govt. Veterinary Surgeons (V.S.) as well as 460 (Four hundred sixty) number of Upazila Livestock Officers (U.L.O.) of DLS were considered as well as selected for overall study population.

Due to time and budget it was not possible to cover all the number of total/overall population. This is why, based upon the total /overall population, the two formulas [i.e. Yamane's mathematical formulae:

$n=\frac{\mathrm{N}}{1+\mathrm{Ne}^{2}}$;

Where

$\mathrm{N}=$ Total number of Population,

$\mathrm{n}=$ sample size and

$\mathrm{e}=$ level of confidence at $5 \%$ and

Random sampling formulae:

$n=\frac{Z^{2} p q}{e^{2}}$

Where,

$\mathrm{n}=$ sample size,

$Z=$ Tabulated value $=1.96$ (For large sample at $5 \%$ level of significance), 
$P=$ estimated population proportion ( 0.5 , this maximizes the sample size),

$q=(1-p), e=$ Margin of error $=0.05]$ were used to determine the study sample size.

Considering both Taro Yamane's mathematical formulae and random sampling technique, the total number of survey sample size for two stakeholder groups were 790 where Group 1 consists 395 respondents and Group 2 consists 395 respondents .

\subsection{Distribution of survey sample}

Considering both Taro Yamane's mathematical formulae and random sampling technique as well as other favorable/convenience factors of survey work, the following distribution and sample size were considered as well as selected for the survey work of this study.

Table 1. Sample size of Group 1 and Group 2 at different division.

\begin{tabular}{lll}
\hline Division Name & Govt. Veterinary Surgeons (Group 1) & $\begin{array}{l}\text { Govt. Upazila Livestock officers (Only Veterinarian, } \\
\text { but not any graduate of Animal husbandry) (Group 2) }\end{array}$ \\
\hline Rangpur & 51 & 51 \\
Rajshahi & 58 & 58 \\
Khulna & 51 & 51 \\
Barishal & 30 & 30 \\
Sylhet & 29 & 29 \\
Chottogram & 74 & 74 \\
Dhaka & 102 & 102 \\
Total & $\mathbf{3 9 5}$ & $\mathbf{3 9 5}$ \\
\hline
\end{tabular}

\subsection{Instrumentation}

The survey keenly took into considerations the use of a questionnaire, structured interviews and observation. Structured interviews were used to get detailed information from the respondents. The survey instrument of this study consisted Likert and Likert-type questions designed to capture the beliefs, knowledge, and practices focus of participants/ respondents using scaled responses. Various closed-ended questions were utilized to collect relevant information of this study.

\subsection{Reliability and validity of the instruments}

Upon the development of survey questions, the instrument was tested for face and content validity by a panel of experts. Revisions to the survey were made based upon feedback from the panel and consisted of re-wording, re-ordering, and removing some questions. The process of establishing instrument validity allowed for linkages between variables and questions to be strengthened. Draft questions were submitted to experts in the field of study for comments before finalizing the questions. To obtain accuracy and reliability to data, care and caution were taken in the course of data collection.

\subsection{Data collection}

Survey instrument was developed for data collection. Survey data were collected from concerning respondents through different means of communication during July 2012 to May 2018. These were mobile phone, telephone, e-mail and direct face to face personal contact. Besides these, Survey data were also collected through workshop, seminar and focus group discussion. The mobile/cell phone, telephone and e-mail details were obtained/collected from both official website of DLS in 2012 and Bangladesh Veterinarians' Directory, 2012.

\subsection{Data analysis}

Respondent data from the surveys were transferred to SPSS (version 20.0, SPSS Inc., Chicago, IL) and quantitative data analysis was completed using the software. Descriptive and inferential statistics were used to analyze the data. Frequency distributions, percentages, means, and standard deviation were utilized as descriptive measures, while independent t-test was the inferential statistics used for data analysis.

\subsection{Parameters studied}

The survey instruments contained the following information's:

A) Factors associated with the poor/weak management in maintaining withdrawal period of veterinary drugs in Bangladesh. 
B) Strategies for maintaining withdrawal period of veterinary drugs in Bangladesh.

\section{Results and Discussion}

3.1. Factors associated with weak/poor management in maintaining withdrawal period of veterinary drugs in Bangladesh

The respondents were requested to indicate their level of agreement to the following statements on 'factors associated with poor management in maintaining withdrawal period of veterinary drugs in the localities of Bangladesh.

The responses were rated on a five point Likert scale where: $1=$ No Role, $2=$ Minimal, $3=$ Not sure, $4=$ Moderate, $5=$ Substantial role.

Data in Table 1 to Table 2 indicated that Veterinary Surgeons of DLS (under study) agreed as well as perceived the following findings /statements.

Economic loss concept: 'Economic loss concept (i.e. The economic loss concept was based on cost-benefit analysis considering economic calculation of input and output in rearing system of farm management) to farmers level due to wastage as well as spoilage of such drug residue containing animal origin products (e.g. egg, milk, meat) which is supposed to occur from the maintenance of withdrawal period of veterinary drugs' had moderate to substantial role for poor management in maintaining withdrawal period of veterinary drugs in the localities of Bangladesh (the mean and median score 4.6101 and 5.0000 respectively).

Lack of compensation support: 'Lack of compensation support among farmers as well as other relevant stakeholders of producer level from DLS and other concerning authorities of GO and NGO' had moderate to substantial role for poor management in maintaining withdrawal period of veterinary drugs in the localities of Bangladesh (the mean and median score 4.6051 and 5.0000 respectively).

Lack of awareness: 'Lack of awareness among farmers, consumers, producers and other relevant stakeholders level who were not conscious about the impact of residual effects of veterinary drugs on public health ' had moderate to substantial role for poor management in maintaining withdrawal period of veterinary drugs in the localities of Bangladesh (the mean and median score 4.5722and 5.0000 respectively).

Weak/poor monitoring system: 'Weak/poor monitoring system of DLS and other concerning authorities of GO and NGO to monitor residues of veterinary drugs in animal origin food' had substantial role for poor management in maintaining withdrawal period of veterinary drugs in the localities of Bangladesh (the mean and median score 4.7544 and 5.0000 respectively).

Lack of proper legislation and guideline: 'Lack of proper legislation and guideline concerning with maintenance of withdrawal period of veterinary drugs' had moderate role for poor management in maintaining withdrawal period of veterinary drugs in the localities of Bangladesh (the mean and median score 4.0127 and 5.0000 respectively).

Lack of ethical motivation: 'Lack of ethical motivation among farmers as well as concerning stakeholders of producer level' had moderate role for poor management in maintaining withdrawal period of veterinary drugs in the localities of Bangladesh (the mean and median score 4.0127 and 5.0000 respectively).

Lack of cooperative and group livestock production as well as marketing system: 'Lack of cooperative and group livestock production as well as marketing system instead of individual/personal system' had moderate to substantial role for poor management in maintaining withdrawal period of veterinary drugs in the localities of Bangladesh (the mean and median score 4.5873 and 5.0000 respectively).

These findings are consistent with the thinking of Barbier, 1987 and Adams, 2006 which support the principles as well as strategies of sustainability where sustainability is interlinked with ecological, social and economic factors. 
Table 2. Factors associated with poor management in maintaining withdrawal period of veterinary drugs in Bangladesh.

\begin{tabular}{lllll}
\hline Parameters & $\begin{array}{l}\text { Economic loss } \\
\text { concept }\end{array}$ & $\begin{array}{l}\text { Lack of compensation } \\
\text { support }\end{array}$ & $\begin{array}{l}\text { Lack of } \\
\text { awareness }\end{array}$ & $\begin{array}{l}\text { Poor monitoring } \\
\text { system }\end{array}$ \\
\hline No. of respondents & 395 & 395 & 395 & 395 \\
Mean & 4.6076 & 4.6051 & 4.5722 & 4.7544 \\
Median & 5.0000 & 5.0000 & 5.0000 & 5.0000 \\
Std. Deviation & 0.63761 & 0.64199 & 0.68466 & 0.53121 \\
\hline
\end{tabular}

Table 3. Factors associated with poor management in maintaining withdrawal period of veterinary drugs in Bangladesh.

\begin{tabular}{llll}
\hline Parameters & $\begin{array}{l}\text { Lack of proper legislation } \\
\text { and guideline }\end{array}$ & $\begin{array}{l}\text { Lack of ethical } \\
\text { motivation }\end{array}$ & $\begin{array}{l}\text { Lack of cooperative and group livestock } \\
\text { production as well as marketing system }\end{array}$ \\
\hline No. of respondents & 395 & 395 & 395 \\
Mean & 4.0127 & 3.9519 & 4.5873 \\
Median & 4.0000 & 4.0000 & 5.0000 \\
Std. Deviation & 0.41218 & 0.66852 & 0.67541 \\
\hline
\end{tabular}

\subsection{Strategies for maintaining withdrawal period of veterinary drugs in Bangladesh}

The respondents were requested to indicate their level of agreement to the following statements on 'strategies for maintaining withdrawal period of drugs in both clinically treated and apparently healthy livestock/ poultry before marketing their products and by-products in the localities of Bangladesh'.

Data in Table 4 and Table 5 indicated that Veterinary Surgeons of DLS (under study) agreed as well as perceived the following findings /statements.

Allocation of compensation: 'Allocation of compensation for the respective farmers as well as other concerning stakeholders' had 'substantial role' in livestock as well as poultry production system for maintaining withdrawal period of drugs in both clinically treated and apparently healthy livestock/ poultry before marketing their products and by-products in the localities of Bangladesh (the mean and median score 4.7899 and 5.0000 respectively).

Allocation of subsidies: 'Allocation of subsidies for the respective farmers as well as other concerning stakeholders' had 'substantial role' in livestock as well as poultry production system for maintaining withdrawal period of drugs in both clinically treated and apparently healthy livestock/ poultry before marketing their products and by-products in the localities of Bangladesh (the mean and median score 4.7443 and 5.0000 respectively).

Providing insurance services: 'Providing insurance services to the respective farmers as well as other concerning stakeholders' had 'substantial role' in livestock as well as poultry production system for maintaining withdrawal period of drugsin both clinically treated and apparently healthy livestock/ poultry before marketing their products and by-products in the localities of Bangladesh (the mean and median score 4.7949 and 5.0000 respectively).

Legal influence: 'Legal influence as well as formulation of concerning punishment Guideline through proper legislation' had 'substantial role' in livestock as well as poultry production system for maintaining withdrawal period of drugs in clinically treated animal/birds before marketing their productsand by-products in the localities of Bangladesh (the mean and median score 4.7595 and 5.0000 respectively).

Allocation of Bank loan with low interest: 'Allocation of Bank loan with low interest for the respective farmers as well as other concerning stakeholders' had 'moderate to substantial role' in livestock as well as poultry production for maintaining withdrawal period of drugs in both clinically treated and apparently healthy livestock/ poultry before marketing their products and by-products in the localities of Bangladesh (the mean and median score 4.5595 and 5.0000 respectively). 
Availability of technology: 'Availability of technology to farmers as well as other concerning stakeholders level for proper utilization instead of wastage/misuse/spoil of veterinary drug residue containing animal origin products (like milk, egg etc.)' had 'substantial role' in livestock as well as poultry production for maintaining withdrawal period of drugs in clinically treated animal/birds before marketing their products in the localities of Bangladesh (the mean and median score 4.7139 and 5.0000 respectively).

Strict surveillance/monitoring: 'Strict surveillance/monitoring by field level office authority of DLS as well as other concerning stakeholders of GO and NGO' had 'substantial role' in livestock as well as poultry production for maintaining withdrawal period of drugs in both clinically treated and apparently healthy livestock/ poultry before marketing their products and by-products in the localities of Bangladesh (the mean and median score 4.7848 and 5.0000 respectively).

Enhancement of monitoring capacity: 'Monitoring capacity enhancement of field level office staff of DLS as well as well as other concerning stakeholders of GO and NGO' had 'substantial role' in livestock as well as poultry production for maintaining withdrawal period of drugs in both clinically treated and apparently healthy livestock/ poultry before marketing their products and by-products in the localities of Bangladesh (the mean and median score 4.7949 and 5.0000 respectively).

Sudden monitoring by vigilant team: 'Sudden monitoring by vigilant team of DLS as sentinel' had 'substantial role' in livestock as well as poultry production for maintaining withdrawal period of drugs in both clinically treated and apparently healthy livestock/ poultry before marketing their products and by-products in the localities of Bangladesh (the mean and median score 4.8025 and 5.0000 respectively).

Magistracy empowerment: 'Magistracy empowerment of veterinarians as well as other concerning staff/members associated with vigilant team of DLS' has 'substantial role' in livestock as well as poultry production for maintaining withdrawal period of drugs in both clinically treated and apparently healthy livestock/ poultry before marketing their products and by-products in the localities of Bangladesh (the mean and median score 4.7899 and 5.0000 respectively).

Motivational type extension work: 'Extension work with motivation for the development of morality/ethics among concerning stakeholders of livestock and poultry production system' had 'substantial role' in livestock as well as poultry production for maintaining withdrawal period of drugs in both clinically treated and apparently healthy livestock/ poultry before marketing their products and by-products in the localities of Bangladesh (the mean and median score 4.7722 and 5.0000 respectively).

Creating public awareness: 'Creating public awareness on drug residue problem in animal origin food by the government, producers, veterinarians, teachers and academicians, marketing associations, and other interested or concerning parties/stakeholders' has 'substantial role' in livestock as well as poultry production for maintaining withdrawal period of drugs in both clinically treated and apparently healthy livestock/ poultry before marketing their products and by-products in the localities of Bangladesh (the mean and median score 4.7722 and 5.0000 respectively.

Availability of effective equipment and modern analytical techniques: 'Availability of effective equipment and modern analytical techniques in DLS and other concerning stakeholders for diagnostic analysis of chemical/drug residues in both animal body and their products' had 'moderate to substantial role' in livestock as well as poultry production for maintaining withdrawal period of drugs in both clinically treated and apparently healthy livestock/ poultry before marketing their products and by-products in the localities of Bangladesh (the mean and median score 4.6532 and 5.0000 respectively)

Availability of trained manpower: 'Availability of trained manpower in DLS and other concerning stakeholders for diagnostic analysis of chemical/drug residues in both animal body and their products' had 'moderate to substantial role' in livestock as well as poultry production for maintaining withdrawal period of drugs in both clinically treated and apparently healthy livestock/ poultry before marketing their products and byproducts in the localities of Bangladesh (the mean and median score 4.5722 and 5.0000 respectively). 
Government regulation and control: 'Government regulation and control for stringent adherence to withdrawal times on-site monitoring for many drugs by institutional intervention' had 'moderate to substantial role' in livestock as well as poultry production for maintaining withdrawal period of Drugsin both clinically treated and apparently healthy livestock/ poultry before marketing their products and by-products in the localities of Bangladesh (the mean and median score 4.5722 and 5.0000 respectively).

Cooperative and group livestock production as well as marketing system: 'Cooperative and group livestock production as well as marketing system instead of individual/personal system' had 'moderate to substantial role' in livestock as well as poultry production for maintaining withdrawal period of drugs in both clinically treated and apparently healthy livestock/ poultry before marketing their products and by-products in the localities of Bangladesh (the mean and median score 4.6051 and 5.0000 respectively).

These findings are consistent with the thinking of Arrow et al., 2004; Pezzey, 1992; Solow, 1993 and Toman, 1998 which support the concept of sustainability where sustainability is interlinked with the wellbeing of society.

Table 4. Strategies for maintaining withdrawal period of drugs in both clinically treated and apparently healthy livestock/ poultry before marketing their products and by-products in the localities of Bangladesh.

\begin{tabular}{lllllll}
\hline Parameters & $\begin{array}{l}\text { Allocation of } \\
\text { compensation }\end{array}$ & $\begin{array}{l}\text { Allocation of } \\
\text { subsidies }\end{array}$ & $\begin{array}{l}\text { Providing } \\
\text { insurance services }\end{array}$ & $\begin{array}{l}\text { Legal } \\
\text { influence }\end{array}$ & $\begin{array}{l}\text { Allocation of Bank } \\
\text { loan with low interest }\end{array}$ & $\begin{array}{l}\text { Availability } \\
\text { of technology }\end{array}$ \\
\hline Respondents & 395 & 395 & 395 & 395 & 395 & 395 \\
Mean & 4.7367 & 4.7443 & 4.7949 & 4.7595 & 4.5595 & 4.7139 \\
Median & 5.0000 & 5.0000 & 5.0000 & 5.0000 & 5.0000 & 5.0000 \\
Std. & 0.567 & 0.545 & 0.489 & 0.528 & 0.647 & 0.553 \\
Deviation & & & & & & \\
\hline
\end{tabular}

Table 5. Strategies for maintaining withdrawal period of drugs in both clinically treated and apparently healthy livestock/ poultry before marketing their products and by-products in the localities of Bangladesh.

\begin{tabular}{llllll}
\hline Parameters & $\begin{array}{l}\text { Strict } \\
\text { surveillance } \\
\text { /monitoring }\end{array}$ & $\begin{array}{l}\text { Enhancement } \\
\text { of monitoring } \\
\text { capacity }\end{array}$ & $\begin{array}{l}\text { Sudden } \\
\text { monitoring by } \\
\text { vigilant team }\end{array}$ & $\begin{array}{l}\text { Magistracy } \\
\text { empowerment }\end{array}$ & $\begin{array}{l}\text { Motivational } \\
\text { type extension } \\
\text { work }\end{array}$ \\
\hline No. of respondents & 395 & 395 & 395 & 395 & 395 \\
Mean & 4.7848 & 4.7949 & 4.8025 & 4.7899 & 4.7722 \\
Median & 5.0000 & 5.0000 & 5.0000 & 5.0000 & 5.0000 \\
Std. Deviation & 0.501 & 0.495 & 0.485 & 0.498 & 0.517 \\
\hline
\end{tabular}

Table 6. Strategies for maintaining withdrawal period of drugs in both clinically treated and apparently healthy livestock/ poultry before marketing their products and by-products in the localities of Bangladesh.

\begin{tabular}{llllll}
\hline Parameters & $\begin{array}{l}\text { Creating } \\
\text { public } \\
\text { awareness }\end{array}$ & $\begin{array}{l}\text { Availability of effective } \\
\text { equipment and } \\
\text { modern analytical } \\
\text { techniques }\end{array}$ & $\begin{array}{l}\text { Availability of } \\
\text { trained } \\
\text { manpower }\end{array}$ & $\begin{array}{l}\text { Government } \\
\text { regulation and } \\
\text { control }\end{array}$ & $\begin{array}{l}\text { Cooperative and } \\
\text { group livestock } \\
\text { production as well } \\
\text { as marketing system }\end{array}$ \\
\hline Respondents & 395 & 395 & 395 & 395 & 395 \\
Mean & 4.6532 & 4.6633 & 4.5722 & 4.6329 & 4.6051 \\
Median & 5.0000 & 5.0000 & 5.0000 & 5.0000 & 5.0000 \\
Std. Deviation & 0.582 & 0.575 & 0.618 & 0.595 & 0.571 \\
\hline
\end{tabular}

3.3. Independent t-test Results on Group Perception about the variable 'factors associated with poor management in maintaining withdrawal period of veterinary drugs in Bangladesh'

The results of the independent t-test found no significant difference in perception scores between the two groups of Govt. Veterinary Surgeons and Govt. Upazila Livestock officers for the variable on "factors associated with poor management in maintaining withdrawal period of veterinary drugs in Bangladesh" $(\mathrm{t}=1.342, \mathrm{p}>.05)$. 
3.4. Independent t-test Results on Group perception about the variable 'strategies for maintaining withdrawal period of Drugs in both clinically treated and apparently healthy livestock/ poultry before marketing their products and by-products in the localities of Bangladesh"

The results of the independent t-test found no significant difference in perception scores between the two groups of Govt. Veterinary Surgeons and Govt. Upazila Livestock officers for the variable on "strategies for maintaining withdrawal period of Drugs in both clinically treated and apparently healthy livestock/ poultry before marketing their products and by-products in the localities of Bangladesh" $(t=1.005, p>.05)$.

\section{Conclusions}

The research findings express that potential stakeholder groups of veterinary services possessed important perceptions across different perspectives/dimensions concerning with the maintenance of withdrawal period of veterinary drugs and generally agreed with the statements within the perspectives/dimensions associated with the maintenance of withdrawal period of veterinary drugs in context of environmental realities in Bangladesh. The intent of this study was not to generalize, but to identify current beliefs and knowledge of Government veterinarians regarding the maintenance of withdrawal period of veterinary drugs. Finally, it is the hope that the descriptive findings of this study will provide valuable insight for veterinary practitioners, and stimulate thought and discussion among the concerning stakeholder groups of veterinary profession.

\section{Conflict of interest}

None to declare.

\section{References}

Adams WM, 2006. The Future of Sustainability: Re-thinking Environment and Development in the Twenty-first Century, International Union for Conservationof Nature, Gland, Switzerland.

Althaus RL, A Torres, A Montero, S Balasch, and MP Molina, 2003. Detection limits of antimicrobials in ewe milk by delvotest photometric measurements. J. Dairy Sci., 86: 457-463.

Amjad and Habib, 2005. Estimation of the Residues of Antibiotics in Poultry Products Available in Local Marketsduring Summer. J. Chem. Soci., 27: 6.

Arrow K, P Dasgupta, L Goulder, G Daily, P Ehrlich, G Heal, S Levin, K Maler, S Schneider, D Starrett, and B Walker, 2004. 'Are we consuming too much?', J. Econ. Persp., 18(3): 147-172.

Barbier E, 1987. The concept of sustainable economic development', Environ. Conserv.,14(2): 101-110.

Beyene T and B Tesega, 2014. Rational veterinary drug use: Its significance in public health. J. Vet. Med. Anim. Health, 6: 302-308.

Crawford LM, 1985. The impact of residues on animal food products and Human Health. Rev. Sci. tech. Off. Int. Epiz., 4: 669-685.

Creswell JW and JLP Clark, 2011. Designing and conducting mixed methods research. SAGE Publications, Inc., USA.

Pezzey J, 1992. Sustainable Development Concepts: An Economic Analysis, Environment Paper No. 2, World Bank, Washington DC.

Islam MM, SML Kabir, YA Sarker, MH Sikder, SKS Islam, AHMT Akhter and MM Hossain, 2016. Risk assessment of chromium levels in broiler feeds and meats from selected farms of Bangladesh. Bangl. J. Vet. Med., 14: 131-134.

Riviere JE and SF Sundlof, 2009. Chemical residues in tissue of food animals. In: Veterinary Pharmacology and Therapeutics. Jim E. Riviere and Mark G. Papich (eds.). willey Blackwell. Usa.1453-1462.

Sarker YA, MM Hasan, TK Paul, SZ Rashid, MN Alam and MH Sikder, 2018. Screening of antibiotic residues in chicken meat in Bangladesh by thin layer chromatography. J. Adv. Vet. Anim. Res., 5: 140-145.

Solow R, 1993. An almost practical step towards sustainability', Resources Policy, September, pp. 162-172.

Takele B, K Abdulkaf, J Tariku, T Fanos and A Dinka, 2015. Assessement on chemicals and drugs residue in dairy and poultry products in Bishoftu and Modjo, central Ethiopia. J. Nutri. Food Sci. S., 13: 003.

Toman M, 1998. Sustainable Decision-making: The State of the Art from an Economics Perspective, Discussion Paper 98-39, Resources for the future, Washington DC. 